\title{
Identification of potential plant-based inhibitor against viral proteases of SARS-CoV-2 through molecular docking, MM-PBSA binding energy calculations and molecular dynamics simulation
}

\author{
Bhaskarjyoti Gogoi ${ }^{1} \cdot$ Purvita Chowdhury ${ }^{2} \cdot$ Nabajyoti Goswami $^{3} \cdot$ Neelutpal Gogoi $^{4} \cdot$ Tufan Naiya ${ }^{5} \cdot$ Pankaj Chetia $^{6}$. \\ Saurov Mahanta ${ }^{7}$. Dipak Chetia ${ }^{4} \cdot$ Bhaben Tanti $^{8} \cdot$ Probodh Borah $^{3} \cdot$ Pratap Jyoti Handique $^{9}$
}

Received: 19 December 2020 / Accepted: 16 March 2021 / Published online: 15 April 2021

(c) The Author(s), under exclusive licence to Springer Nature Switzerland AG 2021

\begin{abstract}
The Coronavirus disease 2019 (COVID-19), caused by the novel coronavirus, SARS-CoV-2, has recently emerged as a pandemic. Here, an attempt has been made through in-silico high throughput screening to explore the antiviral compounds from traditionally used plants for antiviral treatments in India namely, Tea, Neem and Turmeric, as potential inhibitors of two widely studied viral proteases, main protease (Mpro) and papain-like protease (PLpro) of the SARS-CoV-2. Molecular docking study using BIOVIA Discovery Studio 2018 revealed, (-)-epicatechin-3-O-gallate (ECG), a tea polyphenol has a binding affinity toward both the selected receptors, with the lowest CDocker energy $-46.22 \mathrm{kcal} \mathrm{mol}^{-1}$ for SARS-CoV-2 Mpro and CDocker energy $-44.72 \mathrm{kcal} \mathrm{mol}^{-1}$ for SARS-CoV-2 PLpro, respectively. The SARS-CoV-2 Mpro complexed with (-)-epicatechin-3-O-gallate, which had shown the best binding affinity was subjected to molecular dynamics simulations to validate its binding affinity, during which, the root-mean-square-deviation values of SARS-CoV-2 Mpro-Co-crystal ligand (N3) and SARS-CoV-2 Mpro- (-)-epicatechin-3-O-gallate systems were found to be more stable than SARS-CoV-2 Mpro system. Further, (-)-epicatechin-3-O-gallate was subjected to QSAR analysis which predicted $\mathrm{IC}_{50}$ of $0.3281 \mathrm{nM}$ against
\end{abstract}

Bhaskarjyoti Gogoi and Purvita Chowdhury contributed equally.

Saurov Mahanta

saurov.mahanta@gmail.com

1 Department of Biotechnology, Royal Global University, Guwahati, Assam 781035, India

2 Department of Health Research, Model Rural Health Research Unit, Tripura 799035, India

3 Bioinformatics Infrastructure Facility, College of Veterinary Science, Assam Agricultural University, Khanapara, Guwahati, Assam 781025, India

4 Department of Pharmaceutical Sciences, Dibrugarh University, Dibrugarh 786004, India

5 Department of Biotechnology, Maulana Abul Kalam Azad University of Technology, West Bengal 700064, India

6 Department of Life Sciences, Dibrugarh University, Dibrugarh 786004, Assam, India

7 National Institute of Electronics and Information Technology (NIELIT), Guwahati, Assam 781008, India

8 Department of Botany, Gauhati University, Guwahati, Assam 781014, India

9 Department of Biotechnology, Gauhati University, Guwahati, Assam 781014, India 
SARS-CoV-2 Mpro. Overall, (-)-epicatechin-3-O-gallate showed a potential binding affinity with SARS-CoV-2 Mpro and could be proposed as a potential natural compound for COVID-19 treatment.

\section{Graphic abstract}

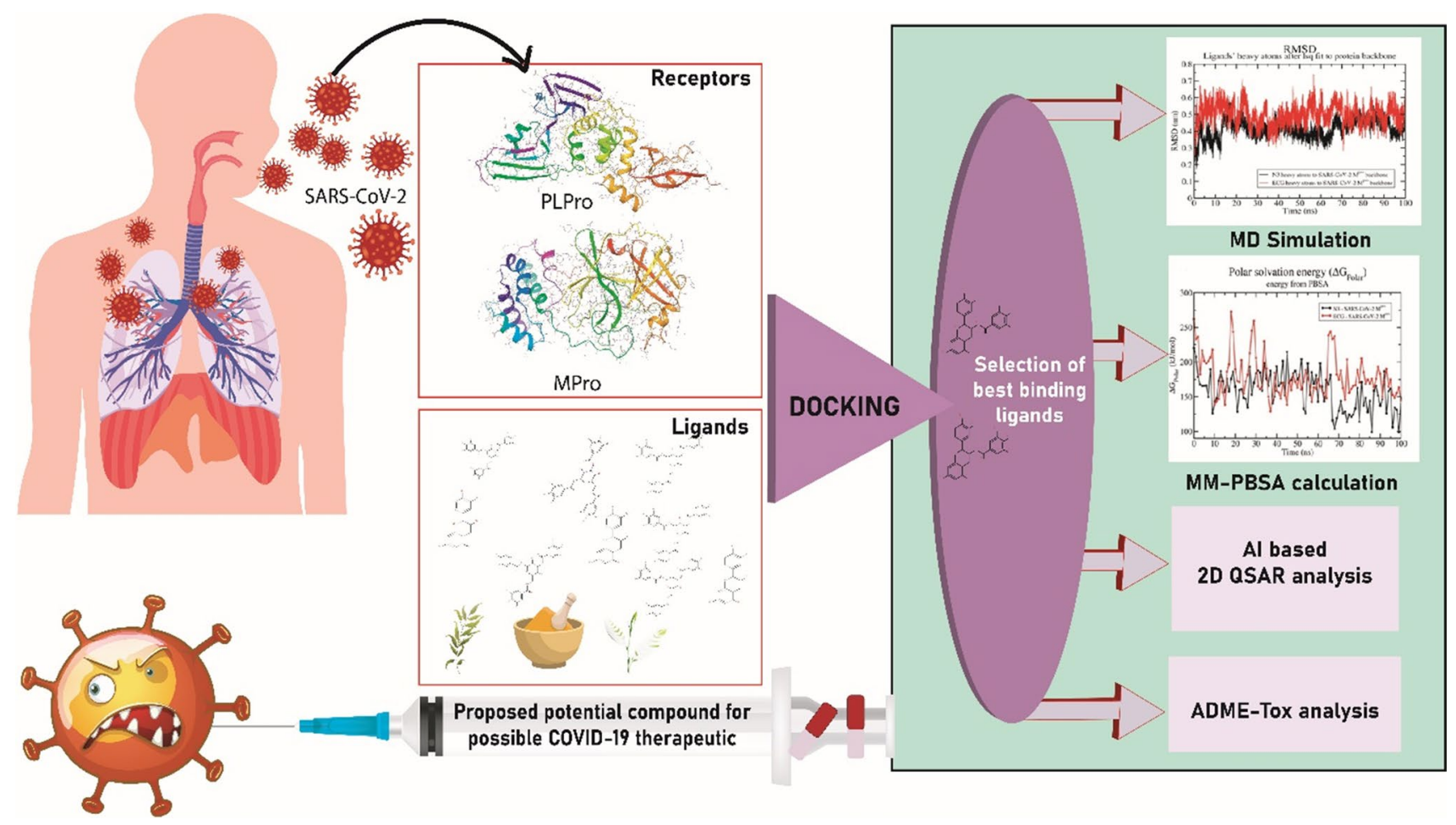

Keywords COVID-19 $\cdot$ SARS-CoV-2 $\cdot$ Main protease $\cdot$ Papain-Like protease (-)-epicatechin-3-O-gallate $\cdot$ Molecular Dynamics · QSAR

\section{Introduction}

Since initially being reported as pneumonia of unknown etiology in Wuhan, China, COVID-2019 has almost crippled the health care system globally and the world has been brought to a standstill. The outbreak caused by a novel coronavirus (CoV), SARS-CoV-2 was declared a Public Health Emergency of International Concern (PHEIC) on January 30, 2020 and a pandemic on March 11, 2020 [1]. With 216 countries, areas or territories affected by the pandemic, cases are escalating with every passing day [2]. According to the World Health Organization (WHO) statistics, as of December 11, 2020, 68,845,368 confirmed cases and 1,570,304 deaths have been reported worldwide [3]. Currently, there is yet no effective treatment or vaccine approved or developed against this SARS-CoV-2 and hence, there is an urgent need for development for effective drugs against this virus $[4,5]$.

Coronaviruses are positive single-stranded RNA viruses of approximately $30 \mathrm{~kb}$ genome size [6]. For effective replication of these viruses, the large viral polyprotein translated using the host cell machinery needs to be cleaved by main protease (Mpro) along with another papain-like protease(s) (PLpro) of virus origin [7]. As inhibition of main protease (Mpro) and PLpro would stop viral replication, these enzymes have become the bestcharacterized drug targets for the coronaviruses [8]. Presence of significant antagonistic effect of host cell immune system, PLpro has become a popular target for its inhibitors [9]. Besides, the Mpro of SARS-CoV-2 shows $96 \%$ similarity with SARS-CoV-1 and also remains as a promising target for the development of new antiviral drugs (Supplementary Fig. 1) [2, 10, 11].

Plant products have been used for generations in Chinese traditional and Indian Ayurvedic medicines for treating viral diseases and the safety of their usage has already been established $[12,13]$. Herbal treatment was also found to be effective during the outbreak of severe acute respiratory syndromes (SARS) in 2003 [14]. Therefore, readily accessible natural compounds with minimum side effects are expected to impede the current outbreak and provide the first line of cure and prevention options [13]. 
In Indian Ayurveda, plants like Tea (Camellia sinensis), Neem (Azadirachta indica) and Turmeric (Curcuma longa) are being widely used for the treatment of viral diseases since ancient era, thereby indicating the presence of active antiviral entities [15-20]. Additionally, these plants are also being used widely for the treatment of viral diseases by the people of different communities of North Eastern part of India traditionally.

The urgency of novel drugs for controlling SARS-CoV-2 generates high demand for computational drug discovery approaches. Virtual screening of natural compounds may provide an alternative approach to identify the potential drug candidate to combat pandemic infectious diseases like novel coronavirus disease, particularly where specific FDA-approved drugs are not available [1, 21, 22]. These approaches offer a great opportunity of testing the hypothesis of potential drug effect of the natural compounds like the other synthetic counterparts. Based on the traditional use as well as on Indian Ayurveda, this study intends to identify putative candidate compound(s) as a potential therapeutic agent for COVID-19 using computational approaches by screening a large number of natural compounds from Tea, Neem and Turmeric functioning as potential inhibitors of the Mpro of SARS-CoV-2.

\section{Materials and methods}

\section{Processing of the crystal structures of the selected receptors}

In the present study, the three-dimensional structure of PLpro was retrieved from RCSB PDB (PDB ID: 6WX4) which was co-crystallized with peptide ligand Vir251. On the other hand, two published structures of SARS-CoV-2 Mpro, cocrystallized with ligands were also downloaded from RCSB Protein Data Bank (PDB), [10, 23]. The PDB IDs of the structures for SARS-CoV-2 Mpro were: (1) 6LU7, SARSCoV-2 Mpro co-crystallized with N3 (a Michael-acceptor inhibitor) and (2) 6Y2G, SARS-CoV-2 Mpro co-crystallized with 13b ( $\alpha$-ketoamide inhibitor) (Supplementary Table 1). To understand the binding pattern of SARS-CoV-2 Mpro with its ligands, the binding site of N3 in 6LU7 was analyzed and compared with the binding site of $13 \mathrm{~b}$ in $6 \mathrm{Y} 2 \mathrm{G}$. Both these ligands were found to bind at a similar binding site of the protein. The same approach was applied for identification of the binding site in case of the SARS-CoV-2 PLpro also, in the crystal structure having PDB ID 6WX4. The structures of SARS-CoV-2 proteases, 6LU7 and 6WX4 were further processed for structure-based analysis. Prior to molecular docking analysis, the target proteins were cleaned by deleting alternate conformations, adjusting the terminal residues and correcting the bond orders. The cleaning process was followed by preparation of the protein for docking analysis. Proteins were prepared by "Prepare Protein" module of "Macromolecules" tool of BIOVIA Discovery Studio (DS) 2018. During the course of protein preparation, the water molecules were removed keeping the target enzymes intact together with their co-crystal ligands. Energy minimization of the protein was performed using CHARMm-based smart energy minimizer of BIOVIA DS 2018 at maximum of 200 steps and $0.1 \mathrm{kcal} \mathrm{mol}^{-1} \mathrm{RMSD}$ gradient [24, 25] for making the structure ready for further analysis.

\section{Processing of the plant-based and synthetic small molecules}

A list of compounds from Tea, Neem and Turmeric were collated from published literatures and phytochemical databases. The 2D structures of the compounds were retrieved from the PubChem Compound Database of NCBI and a library was prepared. The compound library was passed through Lipinski's Drug Discovery filter $[26,27]$ and structures of 1295 shortlisted phytochemicals were converted to $3 \mathrm{D}$ counterparts using the ChemOffice package [28, 29].

The two ligands, namely, N3 and $13 \mathrm{~b}$ bound to SARSCoV-2 Mpro in the crystal structures 6LU7 and 6Y2G, respectively, were taken as controls for in silico binding experiment. These ligands have been previously reported as inhibitors of SARS-CoV-2 Mpro [10, 23]. Similarly, in the case of $6 \mathrm{WX} 4$, the inhibitor Vir251 was used as control during the experiment.

The 3D structures of the ligands were further prepared for docking analysis using "Small Molecule" tool of BIOVIA DS 2018 followed by energy minimization of the compounds with the help of "Full Minimization" module of same tool. The minimization of energy was done using CHARMmbased energy minimizer with 2000 steps of Steepest Descent and Conjugate Gradient algorithm with $0.01 \mathrm{kcal} \mathrm{mol}^{-1}$ RMSD gradient.

\section{Molecular docking}

CHARMm-based smart minimizer method was used to minimize the energy of the target proteins as well as ligands and prepared for docking study using CDocker of BIOVIA Discovery Studio (DS) 2018 [25]. The binding site of N3 and $13 \mathrm{~b}$ ( $\alpha$-ketoamide) to SARS-CoV-2 Mpro was used as the active site for molecular docking study. The coordinates used for binding site of Mpro were X: - 10.897; Y: 13.066; Z: 68.557 with radius $12.738 \AA$. Similarly, the binding site of Vir251 in 6WX4 was considered as the binding site in case of SARS-CoV-2 PLpro. The coordinates for PLpro were X: 8.904; Y: -27.443 ; Z: -37.926 with radius $10.323 \AA$ Af. After molecular docking, the binding energies for ligand-receptor interactions were calculated with the help of 'Calculate 
Binding Energy' protocol of DS 2018. Lower value of CDocker energy gives the best binding affinity of the ligand to the receptor protein [25]. The best binding complexes were then processed for molecular dynamics (MD) simulations to study the stability of the protein-ligand complexes which could mimic the conditions of in vitro and in vivo experiments [31].

\section{Molecular dynamics (MD) simulation and pharmacokinetic analysis}

All MD simulations were conducted using GROMACS 2018.2 package with a united-atom force field (GROMOS96 43a1) [32-38] for a time scale of $100 \mathrm{~ns}$ each at $310 \mathrm{~K}$ $\left(37^{\circ} \mathrm{C}\right)$ on a DELL PowerEdge R740 Rack server machine comprising 40 physical processor cores within two second Generation Intel ${ }^{\circledR}$ Xeon ${ }^{\circledR}$ Gold Scalable processors accelerated by an NVIDIA ${ }^{\circledR}$ Tesla ${ }^{\circledR}$ V100 Tensor Core graphic processor unit (GPU).

For performing the MD Simulations, topology files of the small molecules N3 (co-crystal ligand) and (-)-epicatechin-3-O-gallate (ECG) were obtained from PRODRG [39, 40]. All defined systems were solvated with extended-SPC explicit solvent water model. Four $\mathrm{Na}+$ ions were added to neutralize the system before energy minimization and position restraint MDs (NVT and NPT for 100 ps each). A water box of $5 \AA$ from the surface of the protein was created for all three systems. The systems were neutralized with counter-ions and energy minimization was performed using steepest descent for 50,000 steps. For all three systems (SARS-CoV-2 Mpro, SARS-CoV-2 Mpro-N3, and SARSCoV-2 Mpro-ECG), the protein backbone was frozen and solvent molecules with counter-ions were allowed to move for two $100 \mathrm{ps}$ position restrained equilibration MD runs. All simulations were performed under periodic boundary conditions with NVT followed by NPT ensemble. During the position restraint MD runs, V-rescale and Berendsen's coupling algorithms were used to keep the temperature $(310 \mathrm{~K})$ and pressure (1 bar) constant, respectively. Finally, $100 \mathrm{~ns}$ of production MD runs were performed allowing all molecules to move in all directions according to a classical Newtonian leap-frog MD integrator. For all the systems, the pressure was maintained at 1 bar by isotropic pressure coupling in $x, y$ and $z$ components to a Parrinello-Rahman barostat with the time constant $\tau=2.0 \mathrm{ps}$ and compressibility of $4.5 \times 10-5 \mathrm{bar}^{-1}$ in all three dimensions. The electrostatic interactions were calculated by the PME algorithm, with coulomb cutoff of $12 \AA$ and interpolation order of 4 within a grid spacing of $0.16 \mathrm{~nm}$. The time steps for the simulations were $2 \mathrm{fs}$, and the coordinates were stored every 5 ps. The Van der Waals (vdw) forces were treated using a cutoff of $12 \AA$ with force-switch vdw-modifier and rvdwswitch 1. LINCS algorithm was used to constrain all bond lengths. GNU image manipulation tool 2.8 (GIMP) was used to label and reconstruct the assembled diagrams. Protein-ligand interactions were evaluated by $\mathrm{LigPlot}^{+}$[41]. Further, the pharmacokinetic analysis of the best binding molecule was done using pkCSM [42, 43].

\section{MM-PBSA calculations}

Binding free energies ( $\Delta G_{\text {Bind }}$ ) of the protein-ligand complexes were calculated from molecular mechanics Poisson-Boltzmann surface area (MM-PBSA) evaluated by adaptive Poisson-Boltzmann solver 3.0 (APBS 3.0) using g_mmpbsa package [44, 45]. The MM-PBSA approach is one of the most widely used methods to compute interaction energies among the biomolecular complexes. Together with MD simulation, MM-PBSA can decode significant conformational fluctuations and entropic contributions to the binding energy. In general, the binding free energy $\left(G_{\text {Bind }}\right)$ between a protein and a ligand in solvent can be expressed as:

$\Delta G_{\text {Bind }}=G_{\text {Complex }}-\left(G_{\text {Protein }}+G_{\text {ligand }}\right)$

where $G_{\text {Complex }}$ is the total free energy of the protein - ligand complex and $G_{\text {Protein }}$ and $G_{\text {Ligand }}$ are total free energies of the separated protein and ligand in solvent, respectively. The same equation can be used to calculate other types of biomolecular interactions such as protein - protein, protein - DNA complexes, etc.

\section{HOMO-LUMO energy calculation}

Density functional theory (DFT) analysis was performed in order to determine the electrostatic properties of N3 and ECG. The frontier orbital energies, i.e., highest occupied molecular orbital (HOMO) and lowest unoccupied molecular energy (LUMO) were calculated using Becke's threeparameter exchange functionals (B3LYP) module of Dmol3 package of BIOVIA DS 2018. The HOMO and LUMO energy profile describe the electron donor and acceptor properties of any compounds which ultimately gives the idea on the reactivity of the compounds to their receptors [46]. In this study, by analyzing the HOMO and LUMO energy profile, the energy gap of N3 and ECG was determined.

\section{Quantitative structure-activity relationship (QSAR) analysis}

To study the inhibitory potentiality of ECG, the best binding molecule, a quantitative structure-activity relationship (QSAR) analysis was performed. For the QSAR Study, 21 reported inhibitors were taken from ChEMBL 
BioAssay (CHEMBL854506) database [47, 48]. The molecules were loaded in BIOVIA Discovery Studio 2019 and their energy minimization was done using CHARMm. Total Energy was predicted using the DMol3 module of the Discovery Studio and other descriptors were also calculated [49]. Activities were predicted for each of the molecule using the generated QSAR equation, validated using the test data set and plotted against their experimental activities. As the $\mathrm{R}^{2}$ value for the QSAR Equation was reasonably high, the equation was used to predict the activity of ECG. Similarly, QSAR analysis of N3 was also performed to compare inhibitory potentiality of ECG with N3.

\section{Results and discussion}

The plant molecules with the best binding affinity to SARSCoV-2 Mpro and SARS-CoV-2 PLpro were selected based on lowest CDocker energy values. The result revealed that, among all the plant-based compounds used in the study, a tea polyphenol, ECG showed the lowest CDocker energy for SARS-CoV-2 Mpro, that is, $-46.22 \mathrm{kcal} \mathrm{mol}^{-1}$, followed by Phloretin $\left(-36.36 \mathrm{kcal} \mathrm{mol}^{-1}\right)$ of tea $(C$. sinensis). Interestingly, in case of SARS-CoV-2 PLpro, the same polyphenol, i.e., ECG showed the lowest CDocker energy with value $-44.72 \mathrm{kcal} \mathrm{mol}^{-1}$ followed by Nordihydroguaiaretic acid $\left(-35.37 \mathrm{kcal} \mathrm{mol}^{-1}\right)$ of tea $($ C. sinensis $)$. Based on the CDocker energy, the best compounds having good binding affinity to both the selected receptors are tabulated in Table 1. Since ECG showed the best binding affinity with SARS-CoV-2 Mpro, this complex was considered for further MD simulation.

To compare the binding of ECG with SARS-CoV-2 Mpro with the control, molecular docking was also performed between control molecules and the target proteins. Because ECG showed the highest binding affinity with SARS-CoV-2 Mpro, co-crystal ligands N3 and 13b were allowed to dock with SARS-CoV-2 Mpro. Between the controls, N3 (Supplementary Fig. 2) showed the lowest CDocker energy $\left(-91.37 \mathrm{kcal} \mathrm{mol}^{-1}\right)$ after docking with SARS-CoV-2 Mpro. Surprisingly, the other control, that is, the ligand 13b showed CDocker energy $-40.82 \mathrm{kcal} \mathrm{mol}^{-1}$, which was lower than the CDocker energy of ECG. The co-crystal ligand of PLpro, i.e., Vir251 showed CDocker value $-75.038 \mathrm{kcal} \mathrm{mol}^{-1}$ with its target enzyme. Moreover, the numbers of $\mathrm{H}$-bond formation between the ligand and receptor were analyzed and observed that both SARSCoV-2 Mpro-N3 and SARS-CoV-2 Mpro-ECG complexes were formed with six H-bonds. It is assumed that more numbers of H-bonds give a better tolerance to the mutability of the virus [2]. Because ECG showed the highest binding affinity with Mpro and formed more numbers of H-bonds in comparison to all the test compounds, the complex of SARSCoV-2 Mpro- ECG was taken for further studies, whereas, the complex SARS-CoV-2 Mpro-N3 was taken as control. Therefore, these two complexes were further analyzed by MM-PBSA binding energy calculation during $100 \mathrm{~ns}$ MD simulations to compute the binding behavior of the ligand to the receptor by mimicking in vitro and in vivo conditions $[31,50]$.

From the results obtained from the MM-PBSA analysis, the average binding free energies $\left(\Delta G_{\text {Bind }}\right)$ of SARS-CoV-2 Mpro-N3 and SARS-CoV-2 Mpro-ECG complexes were calculated during the $100 \mathrm{~ns}$ simulation. The resulting $\Delta G_{\text {Bind }}$ of SARS-CoV-2 Mpro-N3 and SARS-CoV-2 Mpro-ECG complexes were found to be $-282.96 \pm 32.97 \mathrm{~kJ} \mathrm{~mol}^{-1}$ and $-192.40 \pm 27.10 \mathrm{~kJ} \mathrm{~mol}^{-1}$, respectively. The details of MM-PBSA calculation of the complexes are summarized in Table 2. The $\Delta G_{\text {Bind }}$ plot of the complexes is depicted in Fig. 1a.

The calculated averages of molecular mechanics potential energy $\left(\Delta E_{\mathrm{MM}}\right)$, polar solvation energy $\left(\Delta G_{\text {Polar }}\right)$ and non-polar solvation energy $\left(\Delta G_{\text {Non-polar }}\right.$ or $\left.\Delta G_{\text {SASA }}\right)$ under $\Delta G_{\mathrm{PB}}$ between the protein and ligand during the simulation were evaluated from MMPBSA calculation. Average $\Delta E_{\mathrm{MM}}$ for SARS-CoV-2 Mpro-N3 and SARS-CoV-2 Mpro-ECG complexes were found to be $-412.21 \pm 41.69$ and $-351.98 \pm 32.10 \mathrm{~kJ} \mathrm{~mol}^{-1}$, respectively, and the average $\Delta G_{\text {Polar }}$ for SARS-CoV-2 Mpro-N3 complex and SARSCoV-2 Mpro-ECG complex were found to be $158.36 \pm 26.85$ and $179.86 \pm 30.32 \mathrm{~kJ} \mathrm{~mol}^{-1}$, respectively. Calculated average of $\Delta G_{\text {Non-polar }}$ or $\Delta G_{\text {SASA }}$ for SARS-CoV-2 Mpro-N3 complex and SARS-CoV-2 Mpro-ECG complex (red) were found to be $-29.11 \pm 1.95$ and $-20.28 \pm 1.11 \mathrm{~kJ} \mathrm{~mol}^{-1}$, respectively. The graphical representations of $\Delta E_{\mathrm{MM}}, \Delta G_{\mathrm{Polar}}$ and $\Delta G_{\text {Non-polar }}$ or $\Delta G_{\mathrm{SASA}}$ as function of time during the simulation are shown in Fig. 1.

To compare the binding of ECG and N3 to SARSCoV-2 Mpro, three MD simulations were performed on three different states (SARS-CoV-2 Mpro, SARS-CoV-2 Mpro-N3 complex, and SARS-CoV-2 Mpro-ECG complex) for $100 \mathrm{~ns}$. In the MD simulations, lower RMSD values give the idea of the conformational stability of the protein-ligand complex [51]. It was observed that the rootmean-square deviations (RMSDs) of SARS-CoV-2 Mpro system (Fig. 2a) were stabilized around $0.45 \mathrm{~nm}$ from $60 \mathrm{~ns}$ onward. Whereas, the RMSDs were stabilized from $30 \mathrm{~ns}$ onward for SARS-CoV-2 Mpro-N3 at $0.4 \mathrm{~nm}$ and SARSCoV-2 Mpro-ECG systems at $0.35 \mathrm{~nm}$ (Fig. 2a). There were less conformational changes in SARS-CoV-2 Mpro-N3 and SARS-CoV-2 Mpro-ECG systems during the simulations in comparison to the SARS-CoV-2 Mpro system. However, RMSD of SARS-CoV-2 Mpro-ECG system was found to be almost similar to RMSD of SARS-CoV-2 Mpro-N3 system. 


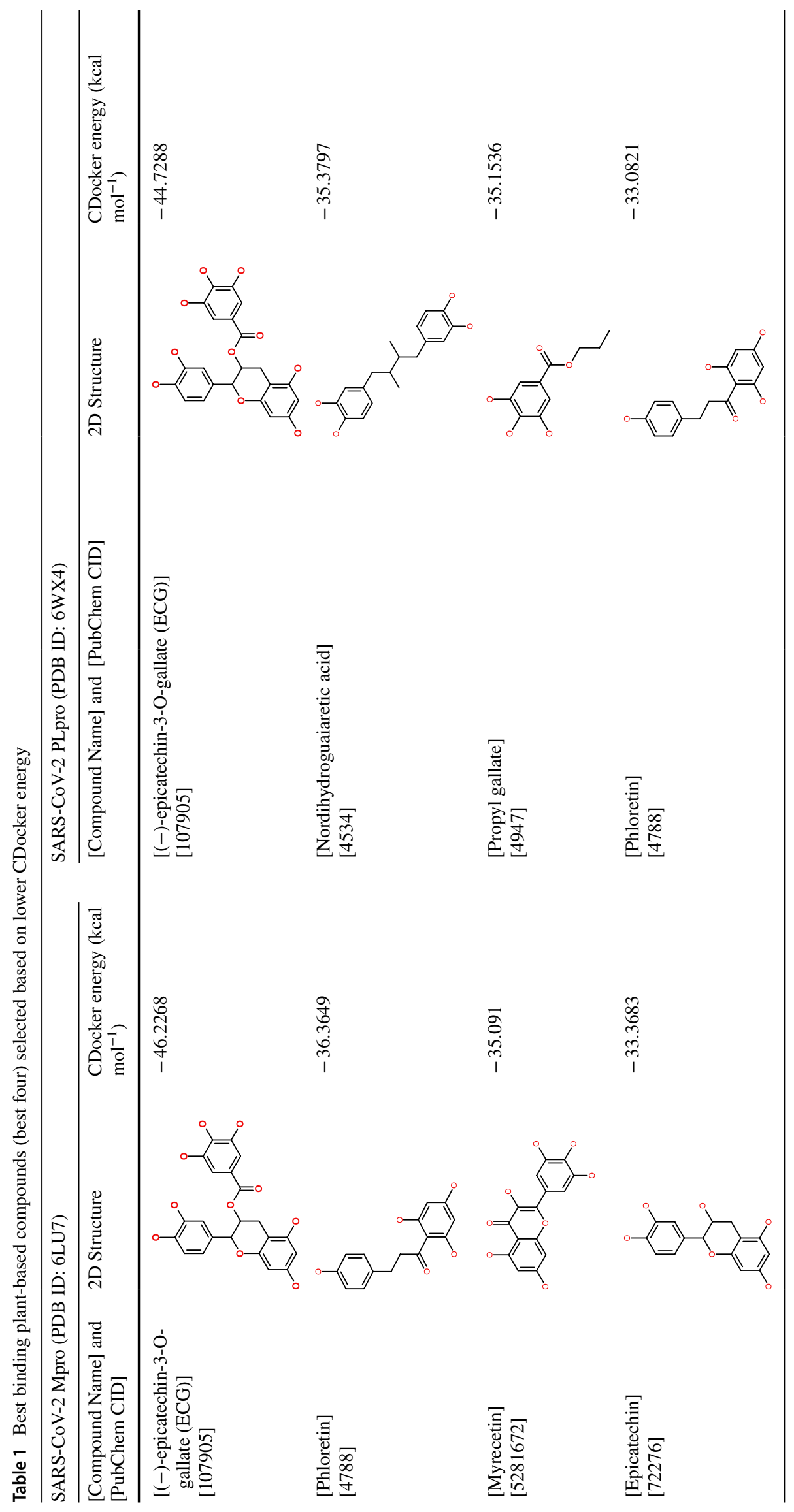


Table 2 Average statistics of MM-PBSA calculation

MMPBSA

\begin{tabular}{|c|c|c|c|c|c|}
\hline \multirow[t]{2}{*}{ Protein-ligand complexes } & \multicolumn{2}{|l|}{$\Delta \mathrm{E}_{\mathrm{MM}}\left(\mathrm{kJ} \mathrm{mol}^{-1}\right)$} & \multicolumn{2}{|l|}{$\Delta \mathrm{G}_{\mathrm{Sol}}\left(\mathrm{kJ} \mathrm{mol}^{-1}\right)$} & \multirow[t]{2}{*}{$\Delta \mathrm{G}_{\text {Bind }}\left(\mathrm{kJ} \mathrm{mol}^{-1}\right)$} \\
\hline & $\Delta \mathrm{E}_{\mathrm{VdW}}\left(\mathrm{kJ} \mathrm{mol}^{-1}\right)$ & $\Delta \mathrm{E}_{\text {Elec }}\left(\mathrm{kJ} \mathrm{mol}^{-1}\right)$ & $\Delta \mathrm{G}_{\mathrm{PB}}\left(\mathrm{kJ} \mathrm{mol}^{-1}\right)$ & $\Delta \mathrm{G}_{\mathrm{SASA}}\left(\mathrm{kJ} \mathrm{mol}^{-1}\right)$ & \\
\hline N3-SARS-CoV-2 Mpro & $-361.67 \pm 33.14$ & $-50.54 \pm 21.37$ & $158.36 \pm 26.85$ & $-29.11 \pm 1.95$ & $-282.96 \pm 32.97$ \\
\hline ECG-SARS-CoV-2 Mpro & $-275.01 \pm 18.68$ & $-76.97 \pm 29.45$ & $179.86 \pm 30.32$ & $-20.28 \pm 1.11$ & $-192.40 \pm 27.10$ \\
\hline
\end{tabular}

$\Delta E_{V d W}$ Van der Waals contribution from MM, $\Delta E_{E l e c}$ electrostatic energy as calculated by the MM force field, $\Delta G_{S o l}$ solvation free energy comprising $\Delta G_{\mathrm{PB}}$, the polar $\left(\Delta G_{\text {polar }}\right)$ and non-polar $\left(\Delta G_{\text {non-polar }}\right)$ solvation free energy contribution calculated by PB equation, $\Delta G_{S A S A}$ the energy contribution from solvent-accessible surface area (SASA), $\Delta G_{B i n d}$ binding free energy
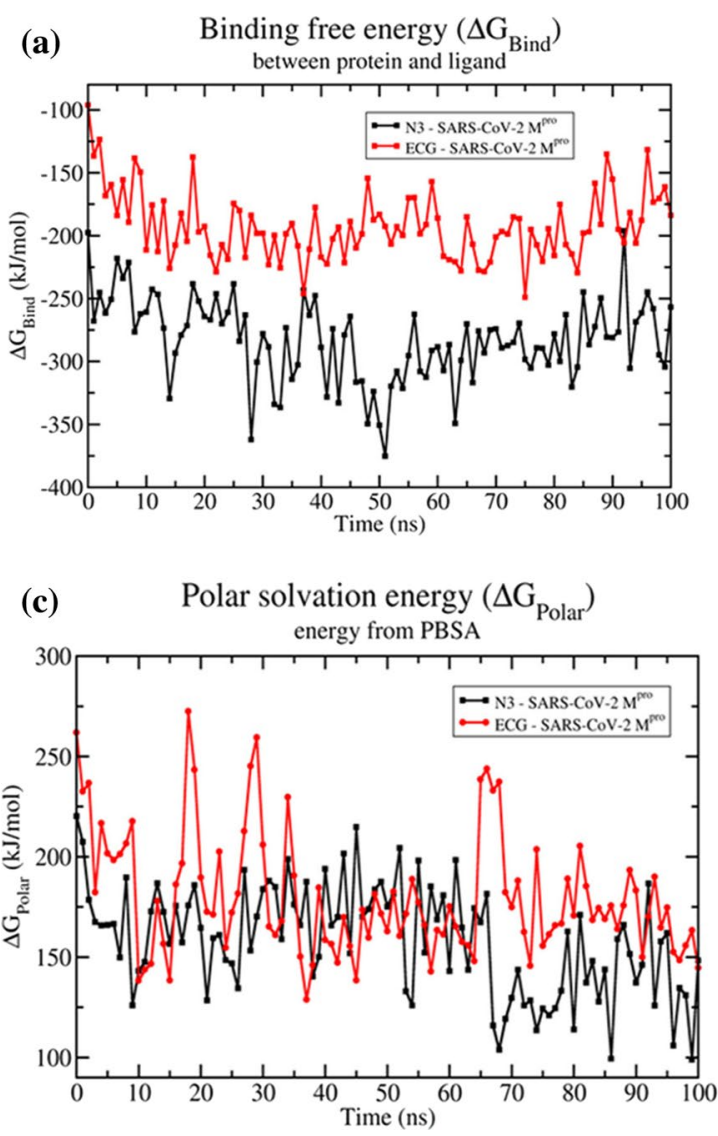

Fig. 1 a Free energy of binding $\left(\Delta G_{\text {Bind }}\right)$, b molecular mechanics potential energy $\left(\Delta E_{\mathrm{MM}}\right)$, c polar solvation energy $\left(\Delta G_{\text {Polar }}\right)$ under $\Delta G_{\mathrm{PB}}$ and d Non-polar solvation energy $\left(\Delta \mathrm{G}_{\text {Non-polar }}\right.$ or $\left.\Delta \mathrm{G}_{\mathrm{SASA}}\right)$ under $\Delta \mathrm{G}_{\mathrm{PB}}$ between the protein and ligand during the simulation was

The RMSDs of the heavy atoms of small molecules N3 and ECG to the backbone of SARS-CoV-2 Mpro indicated that both the ligands were unstable with respect to the protein (Fig. 2b). However, a noticeable relative conformational change was observed in the case of ECG with $\sim 0.7 \mathrm{~nm}$ higher between 56 and $60 \mathrm{~ns}$ than that of the relative conformational change of N3. Additionally, RMSDs of the ligands were calculated by least-square fitting to their simulations
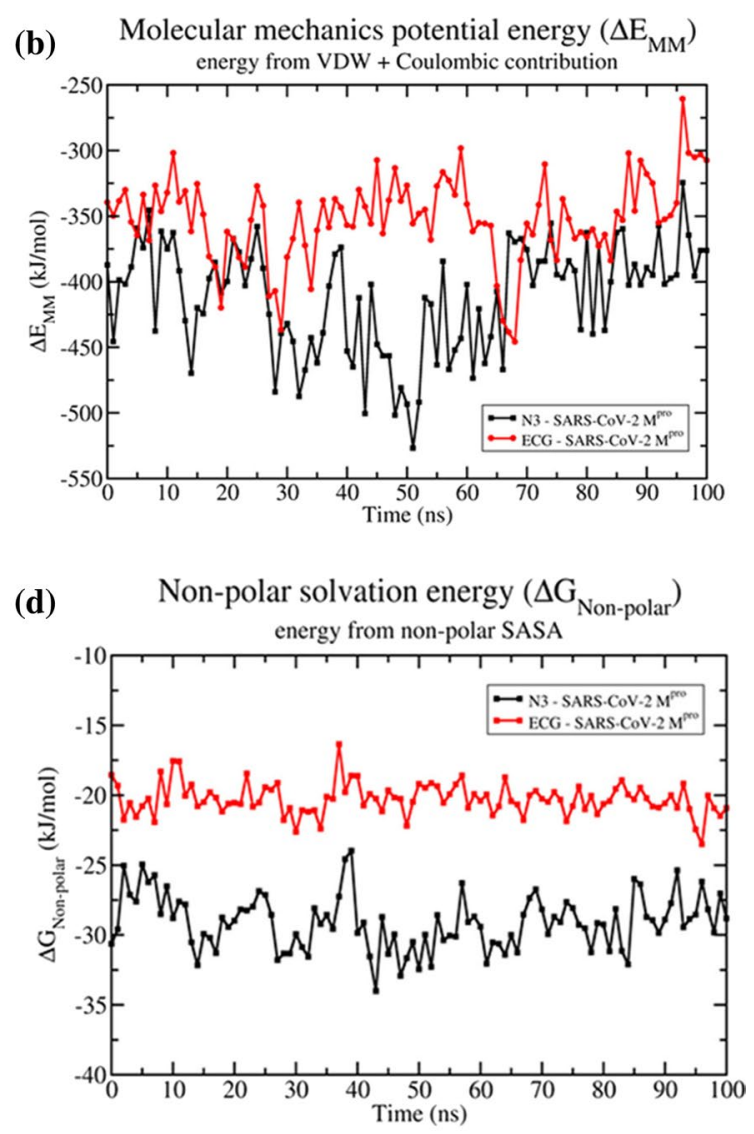

calculated using g_mmpbsa tool. Calculations were performed on the $100 \mathrm{~ns}$ trajectories at the interval of every $1 \mathrm{~ns}$. In all the figures, the black line represents SARS-CoV-2 Mpro -N3 complex and red lone represents SARS-CoV-2 Mpro -ECG

and observed that both ligands also were found to fit similarly to the binding pocket (Supplementary Fig. 3).

To study the conformational stability and protein compactness, radius of gyration ( $\mathrm{Rg}$ ) of the SARS-CoV-2 Mpro protein was calculated in all three states. It was observed that Rg of SARS-CoV-2 Mpro without the ligands (Fig. 2c, black) significantly decreased from $2.2 \mathrm{~nm}$ to $\sim 2.1 \mathrm{~nm}$ and from $55 \mathrm{~ns}$ onward Rg stabilized throughout the simulation. Whereas in case of SARS-CoV-2 Mpro in the presence of N3 

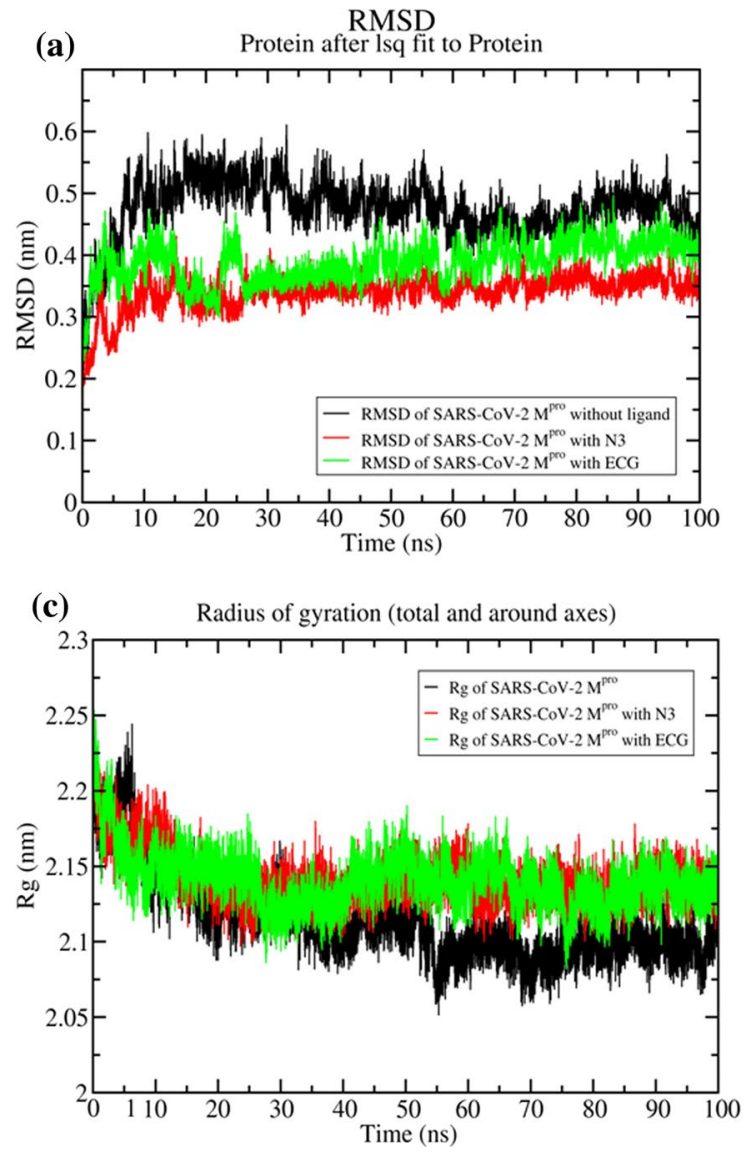

Fig. 2 Analytical depiction of root-mean-square deviation (RMSD) of three systems. a RMSDs of the protein with least-square fit to protein in SARS-CoV-2 Mpro (black), SARS-CoV-2 Mpro-N3 (red) and SARS-CoV-2 Mpro-ECG (green) systems. b RMSDs of the heavy atoms of small molecules N3 (black) and ECG (red) with least-square fit to the protein backbone. $\mathrm{c}$ Radius of gyration (Rg) of SARS-CoV-2 Mpro (black), SARS-CoV-2 Mpro-N3 (red) and SARS-CoV-2 Mpro-

and ECG ligands (Fig. 2c, red and green, respectively), Rgs get stabilized near $2.15 \mathrm{~nm}$ from $30 \mathrm{~ns}$ onward. Although, $\mathrm{Rg}$ reduced drastically in the initial phase, but stable nature of $\mathrm{Rg}$ from $30 \mathrm{~ns}$ onward suggests the stable folding of the protein along with the ligands.

The residue wise root-mean-square fluctuation (RMSF) of SARS-CoV-2 Mpro was calculated for SARS-CoV-2 Mpro-only, SARS-CoV-2-N3 and SARS-CoV-2 Mpro-ECG systems during the course of MD simulation. From Fig. 2d for SARS-CoV-2 Mpro-only plot (black), it was observed that there were distinctly variable peaks in residue positions 21-24, 30-34, 44-56, 92-110, 117-121, 130-145, 182-197 and 220-305 indicating higher fluctuations in these residue locations than that of the SARS-CoV-2-N3 and SARSCoV-2 Mpro-ECG systems. Although the RMSF of SARSCoV-2-N3 and SARS-CoV-2 Mpro-ECG systems revealed almost similar pattern of residue fluctuation, residue positions of 44-50 in SARS-CoV-2-N3 system and residue

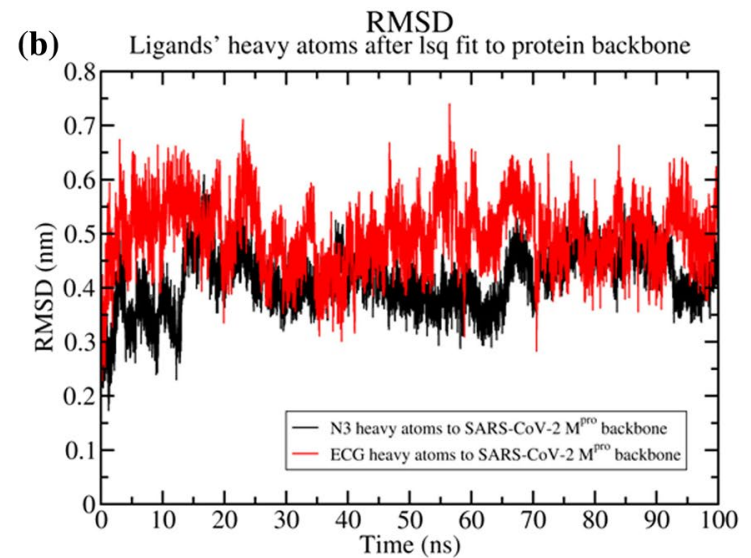

(d)

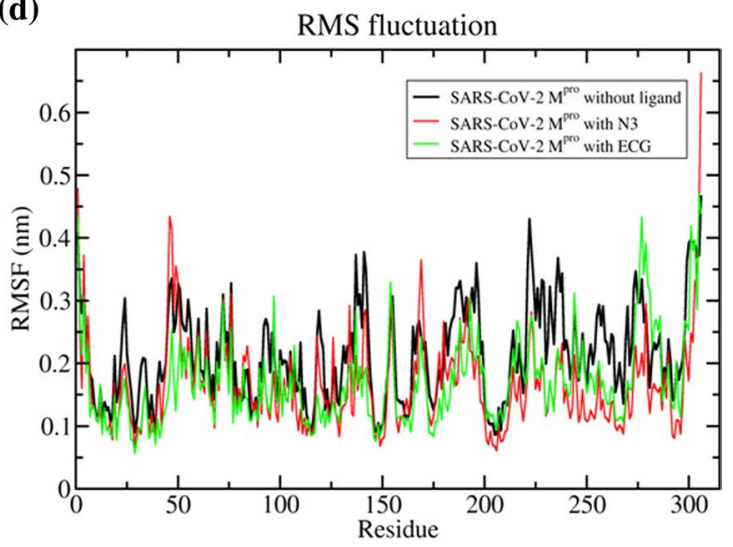

C31 (green) systems. The plot clearly depicts Rg of the three systems by their nature. Ligand-bound systems are seemed to reach their stably folded states earlier than the ligand-free system. d Self-explanatory depiction of root-mean-square fluctuations of SARS-CoV-2 Mpro in SARS-CoV-2 Mpro-only (black), SARS-CoV-2 Mpro-N3 (red) and SARS-CoV-2 Mpro-ECG (green) systems

positions of 271-286 in SARS-CoV-2 Mpro-ECG system were noticeably flexible in the plot (Fig. 2d).

To evaluate the interactions of the ligands with SARSCoV-2 Mpro during the simulation, another two sets of MD simulations of $100 \mathrm{~ns}$ were performed on each of the ligands N3 and ECG with solvent water molecules. It further revealed that the small molecule ECG only exhibits a linear $\mathrm{LJ}$ interaction at around -250 to $-280 \mathrm{~kJ} \mathrm{~mol}^{-1}$ (Fig. 3a). Short-range coulombic interactions seemed to be at the same point for both N3 and ECG (Fig. 3b). From solvent accessible surface area calculation, $\Delta G$ of solvation of SARSCoV-2 Mpro in SARS-CoV-2 Mpro-N3 and SARS-CoV-2 Mpro-ECG systems were deduced and were represented in Supplementary Fig. 4.

Detailed interactions of inhibitors N3 and ECG with SARS-CoV-2 Mpro were studied through molecular visualization using molecular graphics tools like, UCSF Chimera and LigPlot + . The X-ray crystal structure of SARS-CoV- 2 

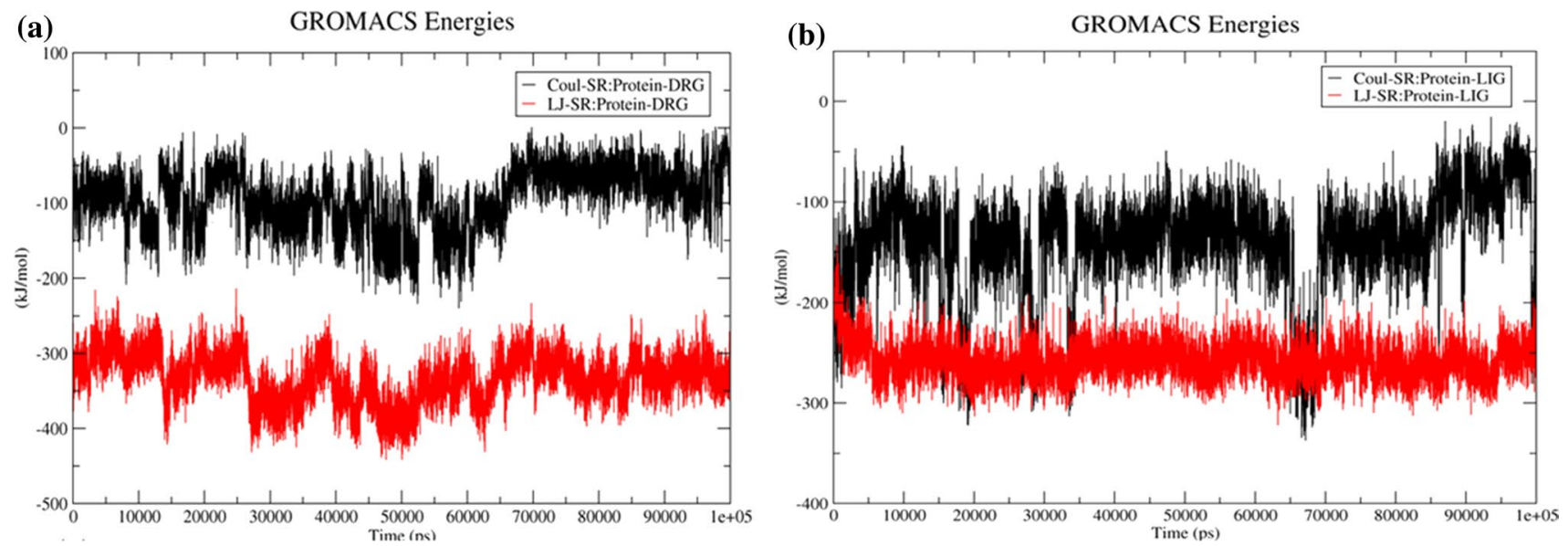

Fig. 3 Protein-ligand interaction analysis. a Short-range coulombic (black) and Lennard-Jones potentials (red) of inhibitor N3 interacting with SARS-CoV-2 Mpro. b Short-range coulombic (black) and Lennard-Jones potentials (red) of inhibitor ECG interacting with SARS-CoV-2 Mpro

Mpro obtained from PDB (PDB ID: 6LU7) revealed the original H-bonding interactions of the inhibitor N3 with the residues Gly143, HIS163, HIS164, GLN166, GLN189 and THR190 (Fig. 4a). Interestingly, after 100 ns of simulation, it was observed that only three residues of SARS-CoV-2 Mpro namely GLU166, ALA191, and GLN192 were involved in H-bonding interactions with inhibitor N3 (Fig. 4b). Nevertheless, the inhibitor N3 remained in the binding pocket of SARS-CoV-2 Mpro due to the strong Van der Waals (VdW) interactions between the residues, GLN189, MET165, HIS163 164, ALA193 194, THR190, ASN142, LEU167, PHE185, HIS41, MET149, LEU50, GLY143, and CYS44. Molecular surface (MS) representation revealed that inhibitor N3 anyhow occupied the binding pocket of SARS-CoV-2 Mpro from 0 to $100 \mathrm{~ns}$ (Fig. 4c, d).

Distances between the atoms of the amino acid residues of SARS-CoV-2 Mpro and atoms of the small molecule were measured using the gmx distance program of GROMACS to evaluate the $\mathrm{H}$ bonding interaction. Calculated distances of the atomic pairs involved in $\mathrm{H}$-bonding are depicted in Fig. $4 \mathrm{a}$, b. Figure $4 \mathrm{e}$, f represents the evolution of H-bonds throughout the simulation with respect to the configuration at $0 \mathrm{~ns}$ and $100 \mathrm{~ns}$.

A similar analysis is presented for SARS-CoV-2 Mpro-ECG complex in Fig. 4. Initially, SARS-CoV-2 Mpro-ECG docked complex possessed six H-bonds, two from PHE140 and SER144 each, one from HIS164 and the other from MET165 (Fig. 5a). However, the residues aforementioned for the inhibitor N3 (shown in Fig. 4) were also contributing strong VdW interactions with ECG. Interestingly at the end of the $100 \mathrm{~ns}$ simulation, the SARSCoV-2 Mpro- ECG complex possessed seven H-bonds. The residues involved in H-bonding with ECG were HIS41, LEU50, GLY143, LEU141, GLU166, ASP187 and GLN189 (Fig. 5b).
On comparing N3-Mpro and ECG-Mpro complexes, it was observed that the inhibitor ECG showed better binding when compared to $\mathrm{N} 3$ in terms of number of H-bonds and the fitness of the molecules at the binding pocket. Fitness of ECG at the binding pocket of SARS-CoV-2 Mpro could be visualized in MS representation in Fig. 5c, $d$ and it was observed that the ECG was going deep inside the pocket during the simulation at $100 \mathrm{~ns}$ (Fig. 5d). Further, ECG was found to attach to the binding pocket of SARS-CoV-2 Mpro more firmly than $\mathrm{N} 3$ with more and consistent numbers of $\mathrm{H}$-bonds with potential residues at SARS-CoV-2 Mpro pocket (Fig. 5e, f).

This analysis indicated that our predicted compound might be more permissive to future mutations. Due to the good binding affinity, (-)-epicatechin-3-O-gallate, an abundant green tea flavonoid [52] might act as a potential inhibitor of SARS-CoV-2 Mpro. pkCSM results also revealed good pharmacokinetic properties of the suggested compound (Supplementary Table 2). This analysis indicated that our predicted compound might be more permissive to future mutations. Due to the good binding affinity, (-)-epicatechin-3-O-gallate, an abundant green tea flavonoid might act as a potential inhibitor of SARS-CoV-2 Mpro. To analyze the drug-like properties of ECG, the pharmacokinetic parameters were studied. For the effectiveness of a drug, satisfying all these parameters are very necessary. In this study, we observed good Caco2 permeability of ECG with $63 \%$ of intestinal absorption. According to the algorithm used in pkCSM, the drugs having more than $30 \%$ intestinal absorption are considered as ideal. In analyzing the various parameters of drug metabolism, it was observed that the compound neither acts as substrate nor as an inhibitor of the different isoforms of Cytochrome P450 except CYP1A2. ECG shows the inhibitory effect on CYP1A2. To analyze the deposition and clearance of the compound, renal OCT2 

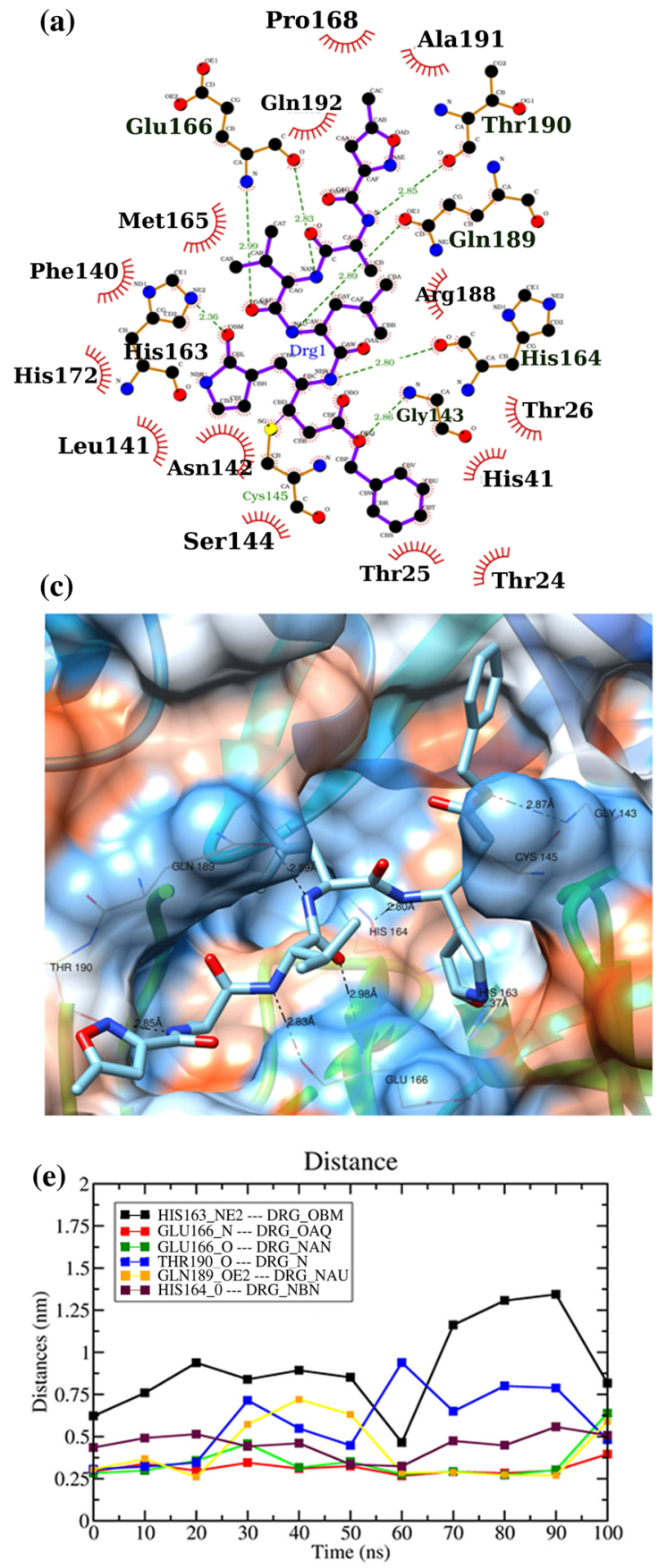

Fig. 4 Interaction of inhibitor N3 (DRG) with the key residues at the binding pocket of SARS-CoV-2 Mpro. a Ligplot depiction of hydrogen bonding and hydrophobic interactions between $\mathrm{N} 3$ and SARS-CoV-2 Mpro as found in PDB entry 6LU7 at its native state. b Ligplot depiction of hydrogen bonding and hydrophobic interactions between N3 and SARS-CoV-2 Mpro as at 100 ns. c Inhibitor $\mathrm{N} 3$ at the binding pocket of SARS-CoV-2 Mpro as found in PDB
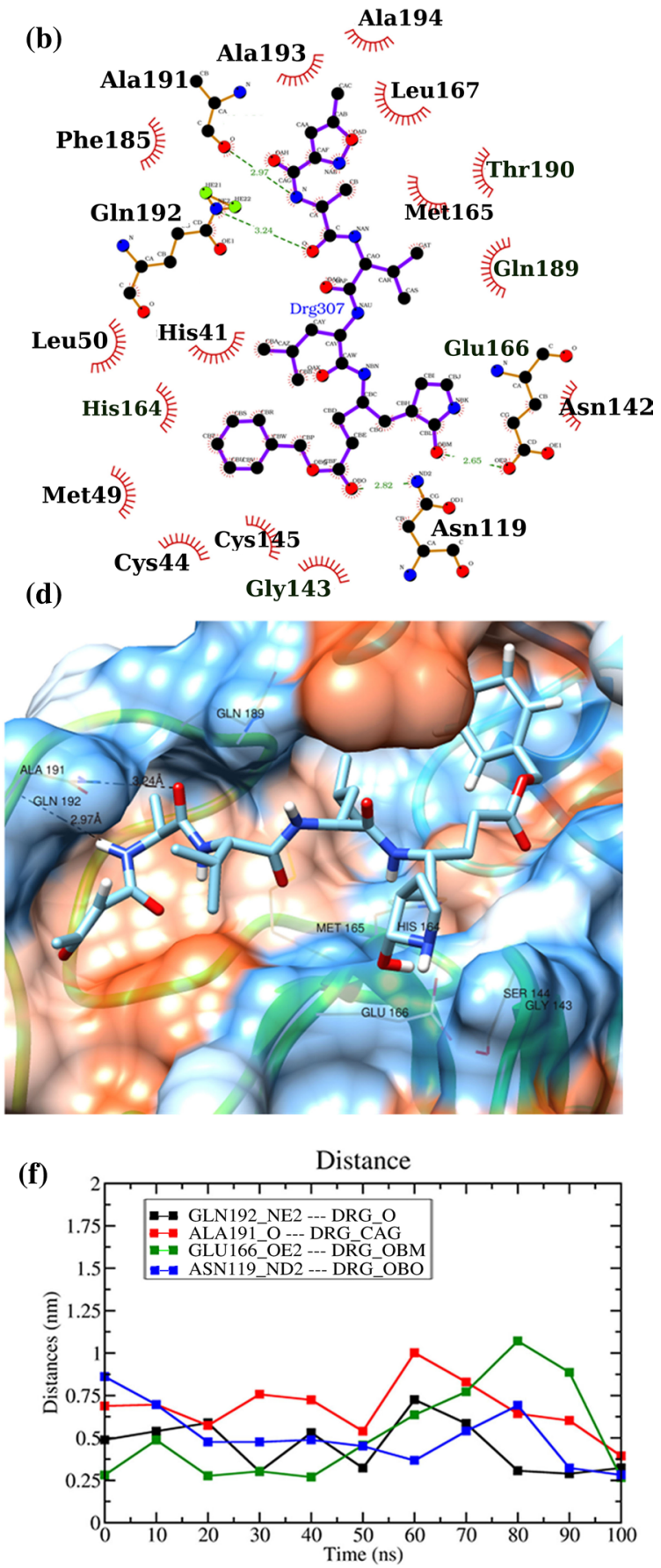

entry 6LU7 at its native state (at $0 \mathrm{ns).} \mathrm{d} \mathrm{Inhibitor} \mathrm{N3} \mathrm{at} \mathrm{the} \mathrm{binding}$ pocket of SARS-CoV-2 Mpro as at $100 \mathrm{~ns}$. e Calculation of distances between the atoms of $\mathrm{N} 3$ and SARS-CoV-2 Mpro residues forming h-bonds depicted from a during the simulation. $\mathbf{f}$ Calculation of distances between the atoms of $\mathrm{N} 3$ and SARS-CoV-2 Mpro residues forming h-bonds depicted from $\mathbf{b}$ during the simulation substrate activity of the compound was analyzed. ECG did not show the substrate activity for renal OCT2. Apart from that, the toxicity assessment of ECG was done by analyzing 

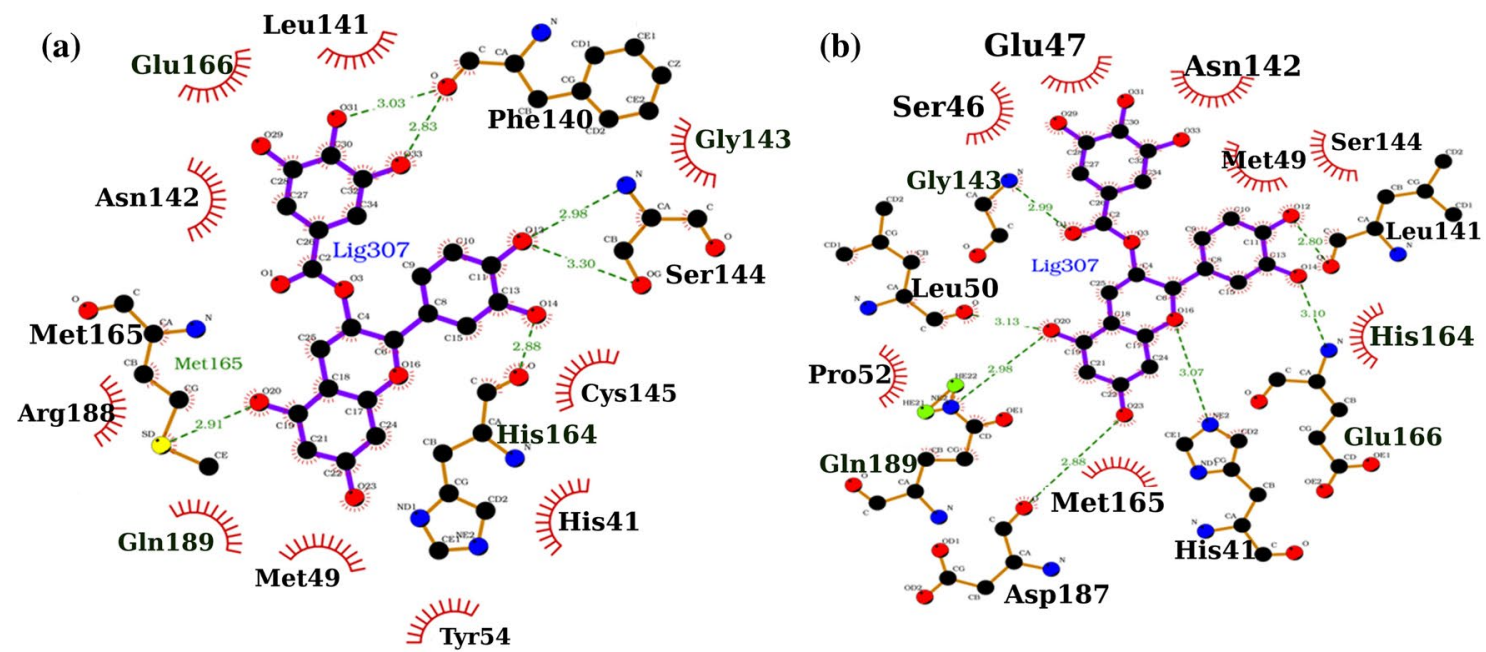

(c)

(d)
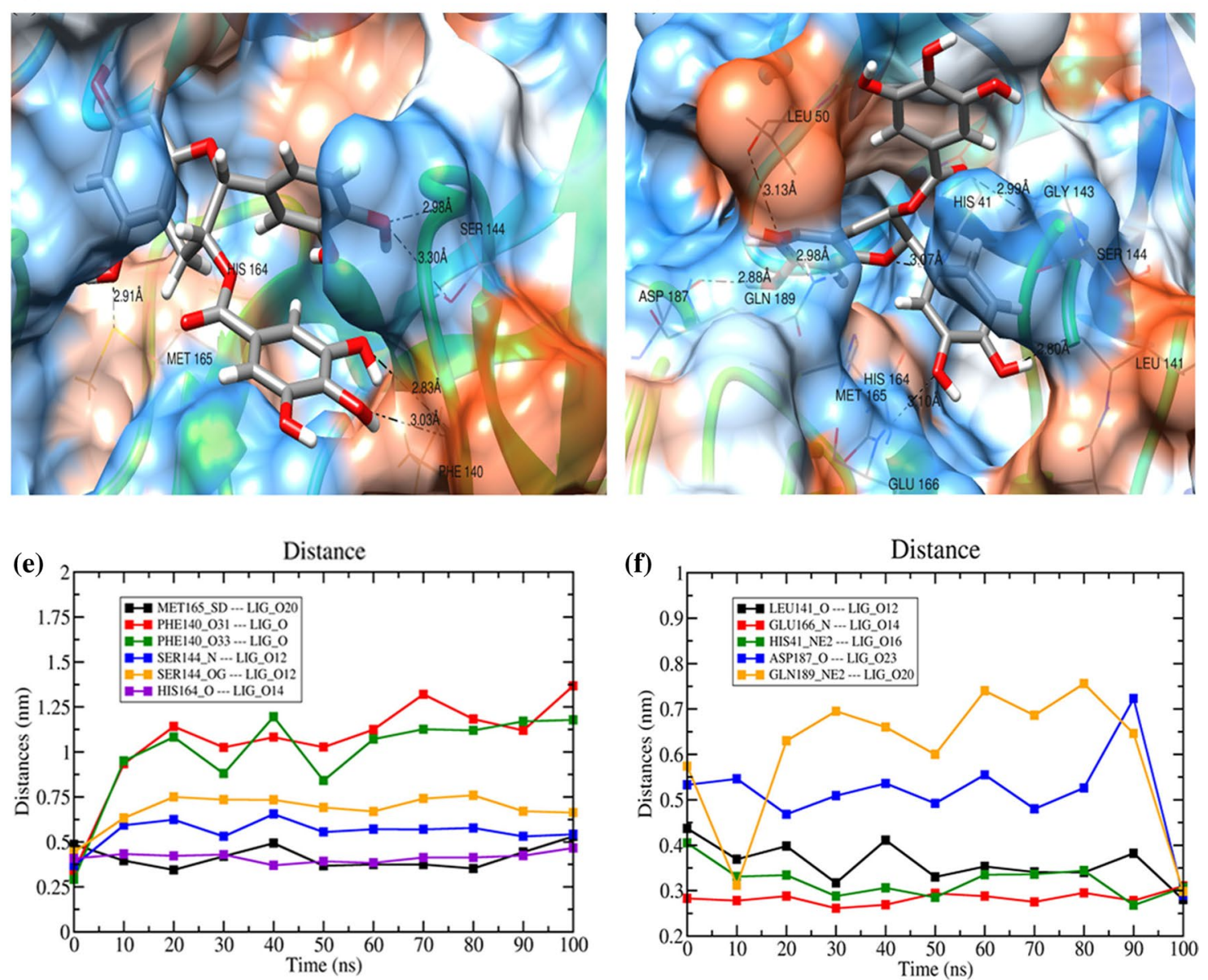

Fig. 5 Interaction of inhibitor ECG (LIG) with the key residues at the binding pocket of SARS-CoV-2 Mpro. a Ligplot depiction of hydrogen bonding and hydrophobic interactions between ECG and SARSCoV-2 Mpro at its native state from docking experiment. b Ligplot depiction of hydrogen bonding and hydrophobic interactions between ECG and SARS-CoV-2 Mpro at 100 ns. c Inhibitor ECG at the binding pocket of SARS-CoV-2 Mpro at its native state from docking

experiment (at $0 \mathrm{~ns}$ ). d Inhibitor ECG at the binding pocket of SARSCoV-2 Mpro at $100 \mathrm{~ns}$. e Calculation of distances between the atoms of ECG and SARS-CoV-2 Mpro residues forming h-bonds depicted from a during the simulation. $\mathbf{f}$ Calculation of distances between the atoms of ECG and SARS-CoV-2 Mpro residues forming H-bonds depicted from $\mathbf{b}$ during the simulation 
AMES toxicity, hepatotoxicity and hERGI/II inhibitory activity. From the results, it was observed that ECG did not show any carcinogenic activity in ADME-Tox study without having a hepatotoxic effect. It has hERGII inhibition activity while it did not show any inhibitory activity for hERGI. The results of pharmacokinetic parameters are given in Supplementary Table 2. Depending on the various parameters mentioned above, the compound can be considered easily for developing into an independent drug molecule.

The HOMO and LUMO frontier orbital energies of N3 and ECG were calculated by DFT analysis. The calculated HOMO and LUMO energies of N3 and ECG obtained from

Table 3 Comparison of the values of orbital energy descriptors HOMO and LUMO

\begin{tabular}{llll}
\hline Molecule & $\begin{array}{l}\text { HOMO energy } \\
(\mathrm{au})\end{array}$ & $\begin{array}{l}\text { LUMO energy } \\
(\mathrm{au})\end{array}$ & Energy gap (eV) \\
\hline N3 & -0.18692 & -0.095238 & 0.091682 \\
ECG & -0.19072 & -0.0829372 & 0.107783 \\
\hline
\end{tabular}

the DFT are given in Table 3. These physical parameters provide the information on the chemical and biological activities of the compounds. The decreased HOMO-LUMO gap or energy gap indicates the higher reactivity of the compound with lesser stability [53]. From the calculated HOMO and LUMO energies, the energy gap of the compounds was calculated and observed that the energy gap of ECG $(0.107783 \mathrm{eV})$ is slightly higher than the co-crystal ligand $\mathrm{N} 3(0.091682 \mathrm{eV})$ indicating similar reactive nature of ECG with N3.

Since both N3 and ECG showed almost similar reactivity, therefore we further determined the $\mathrm{IC}_{50}$ value of ECG and N3 by performing QSAR analysis. During QSAR analysis, out of 21 inhibitors, the training set was randomly generated with $80 \%$ molecules (17 inhibitors) and rest were kept as a test set for validation of the model. A total of 100 QSAR models were generated using genetic function approximation model and the best model having $R^{2}$ value of $88.02 \%$ was selected (adjusted $R^{2}=84.02 \%$ ) (Supplementary Table 3).

The generated QSAR equation was: ${ }^{\prime} \log \left(\mathrm{IC}_{50}\right)^{-1}=-7.0395+0.014618 *$

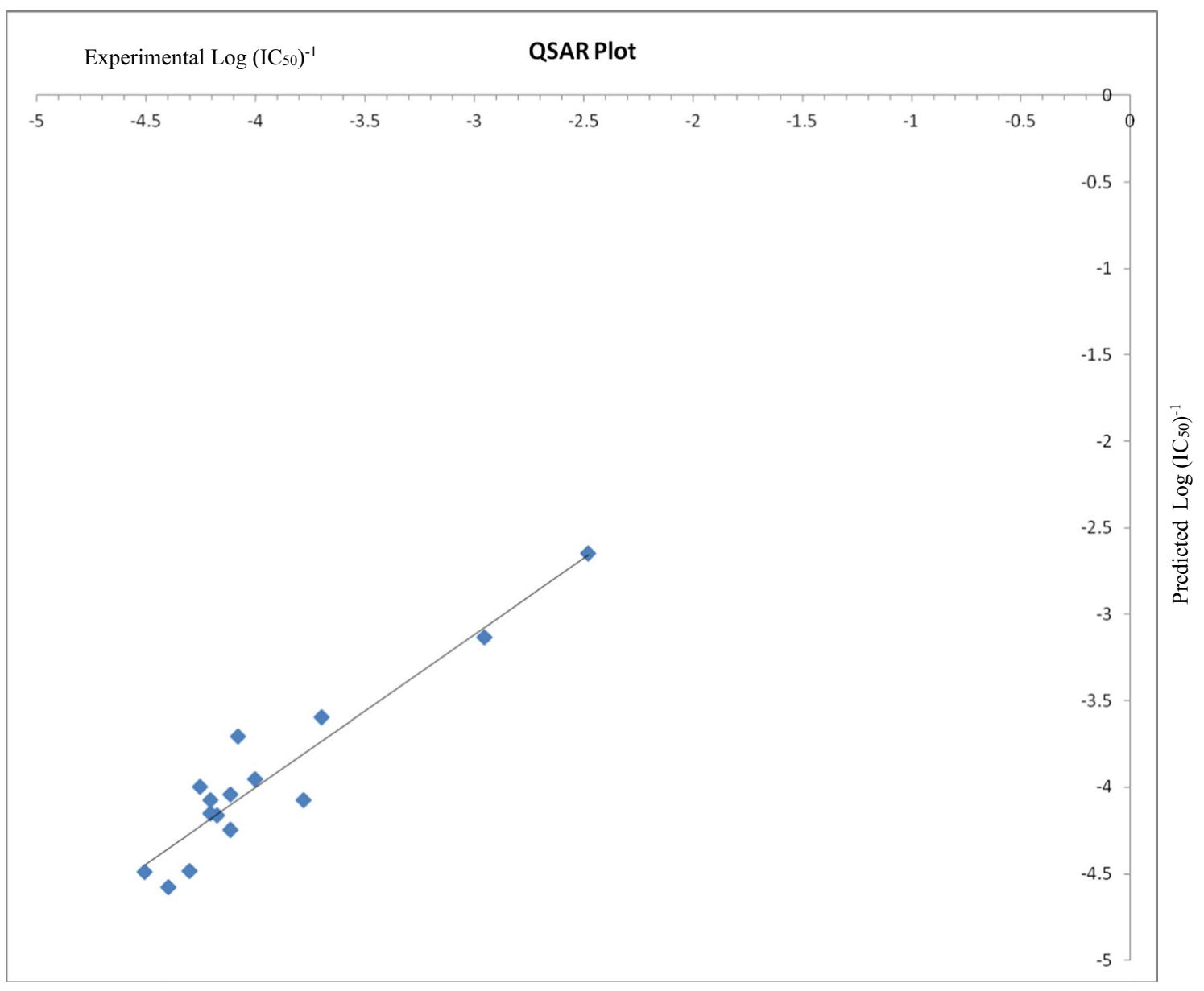

Fig.6 QSAR Plot showing Experimental Activity $\left[\log \left(\mathrm{IC}_{50}\right)^{-1}\right]$ against Predicted Activity $\left[\log \left(\mathrm{IC}_{50}\right)^{-1}\right]$ 
Molecular_Weight $-0.2866 *$ Num_Rotatable Bonds $-0.0051847 *$ CHARMm Energy +0.00042285

*Total_Energy_DMol3".

Further, the activity of ECG and N3 against SARS-CoV-2 Mpro was predicted using the QSAR equation by generating the plot presented in Fig. 6.

For analyzing the activity of ECG and N3, the molecules were minimized using the same CHARMm module and requisite descriptors were calculated in Discovery Studio 2019. The calculated descriptors for ECG were: Molecular_Weight $=442.372$, Numbers of _Rotatable Bonds $=4$, CHARMm Energy $=-62.6023$, Total_Energy_DMol3 $=-1588.42$ and for N3: Molecular_Weight $=680.791$, Numbers of _Rotatable Bonds $=18$, CHARMm Energy $=-117.884$, Total_Energy_ $\mathrm{DMol} 3=-2273.32$. After putting these variables in the QSAR Equation as mentioned above, predicted $\mathrm{IC}_{50}$ value for ECG was found to be $0.3281 \mathrm{nM}$ whereas predicted $\mathrm{IC}_{50}$ value for $\mathrm{N} 3$ was $394.982 \mathrm{nM}$. These results suggest the presence of more inhibitory potential in ECG for SARSCoV-2 Mpro in comparison to N3.

\section{Conclusion}

Docking results revealed that ECG exhibited the lowest CDocker energy with value $-44.72 \mathrm{kcal} \mathrm{mol}^{-1}$ or $-187.108 \mathrm{~kJ} \mathrm{~mol}^{-1}$ which was further validated by MMPBSA analysis and could be correlated to the average of $\Delta G_{\text {Bind }}$ that was found to be $-192.40 \pm 27.10 \mathrm{~kJ} \mathrm{~mol}^{-1}$ during $100 \mathrm{~ns}$ MD simulation. However, the average of $\Delta G_{\text {Bind }}$ of N3 calculated by MMPBSA method during MD simulation was found to be underestimated as $-282.96 \pm 32.97 \mathrm{~kJ} \mathrm{~mol}^{-1}$ as CDocker energy during docking was found to be $-91.37 \mathrm{k} \mathrm{kcal} \mathrm{mol}^{-1}$ or $-382.29 \mathrm{~kJ} \mathrm{~mol}^{-1}$. Nevertheless, N3 possessed stronger binding affinity toward SARS-CoV-2 Mpro, but taking into account of ECG at the binding pocket of the enzyme, the RMSDs profile of the heavy atoms of N3 and ECG to the backbone of SARS-CoV-2 Mpro indicated that both the ligands were unstable with respect to the protein (Fig. 2b). Moreover, the RMSF analysis revealed the most flexible residue positions as 44-50 and 271-286 in SARS-CoV-2-N3 and SARS-CoV-2 Mpro- ECG systems, respectively. From molecular visualization of SARSCoV-2-N3 and SARS-CoV-2 Mpro-ECG systems, it was revealed that the inhibitor ECG conferred better binding in comparison to $\mathrm{N} 3$ in terms of number of $\mathrm{H}$-bonds and the fitness of the molecules at the binding pocket. ECG was found be located inside the binding pocket of SARS-CoV-2 Mpro more firmly than N3 with more and consistent numbers of H-bonds with potential residues at SARS-CoV-2 Mpro pocket (Fig. 5e, f).
Based on the series of computational analysis including molecular docking, MD simulation analysis and subsequent QSAR analysis, we propose ECG as a potential inhibitor of SARS-CoV-2 Mpro with predicted $\mathrm{IC}_{50}$ value of $0.3281 \mathrm{nM}$. In this current situation, a synergistic approach seems to be the most plausible choice for mitigating the spread of the pandemic. Although this study is solely based on in silico predictions and the results need further in vitro and in vivo validations, the present findings may positively contribute to the current global search for inhibitors of SARS-CoV-2 Mpro.

Supplementary Information The online version contains supplementary material available at https://doi.org/10.1007/s11030-021-10211-9.

Acknowledgements The authors would like to thank Mr Pratik Chowdhury for his assistance in language editing of the manuscript.

Author contributions SM was the leader of this study. BT, PB, DC and PJH designed the experiments and coordinated the work. SM, BG, PC, NG, NG, TN and PC performed all the experiments. BG, PC, SM, NG and TN prepared the manuscript. All of the authors read and approved the final manuscript.

Funding The study was not funded by any funding agencies.

\section{Declarations}

Conflict of interest The authors declare no competing interests.

\section{References}

1. Elmezayen AD, Al-Obaidi A, Şahin AT, Yelekçi K (2020) Drug repurposing for coronavirus (COVID-19): in silico screening of known drugs against coronavirus 3CL hydrolase and protease enzymes. J Biomol Struct Dyn. https://doi.org/10.1080/07391 102.2020.1758791

2. Liu X, Wang XJ (2020) Potential inhibitors against 2019-nCoV coronavirus $\mathrm{M}$ protease from clinically approved medicines. J Genet Genomics 47:119-121. https://doi.org/10.1016/j.jgg.2020. 02.001

3. Organization WH (2020) Laboratory testing for coronavirus disease 2019 (COVID-19) in suspected human cases: interim guidance, 2 March 2020. World Health Organization. https://apps.who. int/iris/bitstream/handle/10665/331501/WHO-COVID-19-labor atory-2020.5-eng.pdf

4. Mahanta S, Chowdhury P, Gogoi N et al (2020) Potential antiviral activity of approved repurposed drug against main protease of SARS-CoV-2: an in silico based approach. J Biomol Struct Dyn. https://doi.org/10.1080/07391102.2020.1768902

5. Aanouz I, Belhassan A, El-Khatabi K et al (2020) Moroccan Medicinal plants as inhibitors against SARS-CoV-2 main protease: Computational investigations. J Biomol Struct Dyn. https:// doi.org/10.1080/07391102.2020.1758790

6. Sinha SK, Shakya A, Prasad SK et al (2020) An in-silico evaluation of different Saikosaponins for their potency against SARSCoV-2 using NSP15 and fusion spike glycoprotein as targets. J Biomol Struct Dyn. https://doi.org/10.1080/07391102.2020.17627 41 
7. Fehr AR, Perlman S (2015) Coronaviruses: an overview of their replication and pathogenesis. In: Coronaviruses. pp 1-23. Springer, Berlin. Doi: https://doi.org/10.1007/ 978-1-4939-2438-7_1

8. Báez-Santos YM, John SES, Mesecar AD (2015) The SARS-coronavirus papain-like protease: structure, function and inhibition by designed antiviral compounds. Antiviral Res 115:21-38. https:// doi.org/10.1016/j.antiviral.2014.12.015

9. Wu C, Liu Y, Yang Y et al (2020) Analysis of therapeutic targets for SARS-CoV-2 and discovery of potential drugs by computational methods. Acta Pharm Sin B. https://doi.org/10.1016/j.apsb. 2020.02.008

10. Zhang L, Lin D, Sun X et al (2020) Crystal structure of SARS$\mathrm{CoV}-2$ main protease provides a basis for design of improved $\alpha$-ketoamide inhibitors. Science 368:409-412. https://doi.org/10. 1126/science.abb3405

11. Khan SA, Zia K, Ashraf S et al (2020) Identification of chymotrypsin-like protease inhibitors of SARS-CoV-2 via integrated computational approach. J Biomol Struct Dyn. https://doi.org/ 10.1080/07391102.2020.1751298

12. Chen $\mathrm{C}-\mathrm{N}$, Lin CPC, Huang K-K et al (2005) Inhibition of SARSCoV 3C-like protease activity by theaflavin-3, 3'-digallate (TF3). Evidence-Based Complement Altern Med 2:209-215. https://doi. org/10.1093/ecam/neh081

13. Umesh KD, Selvaraj $C$ et al (2020) Identification of new antinCoV drug chemical compounds from Indian spices exploiting SARS-CoV-2 main protease as target. J Biomol Struct Dyn. https://doi.org/10.1080/07391102.2020.1763202

14. Lau TF, Leung PC, Wong ELY et al (2005) Using herbal medicine as a means of prevention experience during the SARS crisis. Am J Chin Med 33:345-356. https://doi.org/10.1142/S0192415X0 5002965

15. Ahmad A, Javed MR, Rao AQ, Husnain T (2016) Designing and screening of universal drug from neem (Azadirachta indica) and standard drug chemicals against influenza virus nucleoprotein. BMC Complement Altern Med 16:519. https://doi.org/10.1186/ s12906-016-1469-2

16. Bhardwaj VK, Singh R, Sharma J et al (2020) Identification of bioactive molecules from Tea plant as SARS-CoV-2 main protease inhibitors. J Biomol Struct Dyn. https://doi.org/10.1080/ 07391102.2020 .1766572

17. Lin L-T, Hsu W-C, Lin C-C (2014) Antiviral natural products and herbal medicines. J Tradit Complement Med 4:24-35. https://doi. org/10.4103/2225-4110.124335

18. Chen Z, Nakamura T (2004) Statistical evidence for the usefulness of Chinese medicine in the treatment of SARS. Phyther Res An Int J Devoted to Pharmacol Toxicol Eval Nat Prod Deriv 18:592-594. https://doi.org/10.1002/ptr.1485

19. Pantoja P, Pérez-Guzmán EX, Rodríguez IV et al (2017) Zika virus pathogenesis in rhesus macaques is unaffected by pre-existing immunity to dengue virus. Nat Commun 8:1-13. https://doi. org/10.1038/ncomms 15674

20. Rocha FAC, de Assis MR (2020) Curcumin as a potential treatment for COVID-19. Phyther Res. https://doi.org/10.1002/ptr. 6745

21. Boopathi S, Poma AB, Kolandaivel P (2020) Novel 2019 coronavirus structure, mechanism of action, antiviral drug promises and rule out against its treatment. J Biomol Struct Dy. https://doi.org/ 10.1080/07391102.2020.1758788

22. Gupta MK, Vemula S, Donde R et al (2020) In-silico approaches to detect inhibitors of the human severe acute respiratory syndrome coronavirus envelope protein ion channel. J Biomol Struct Dyn. https://doi.org/10.1080/07391102.2020.1751300

23. Jin Z, Du X, Xu Y et al (2020) Structure of Mpro from SARSCoV-2 and discovery of its inhibitors. Nature. https://doi.org/10. 1038/s41586-020-2223-y
24. Gogoi N, Chetia D, Gogoi B, Das A (2019) Multiple-targets Directed Screening of Flavonoid Compounds from Citrus Species to find out Antimalarial Lead with Predicted Mode of Action: An In Silico and Whole Cell-based In vitro Approach. Curr Comput Aided Drug Des. https://doi.org/10.2174/15734099166661912261 03000

25. Abdel-Hamid MK, McCluskey A (2014) In Silico docking, molecular dynamics and binding energy insights into the bolinaquinoneclathrin terminal domain binding site. Molecules 19:6609-6622. https://doi.org/10.3390/molecules19056609

26. Lipinski CA, Lombardo F, Dominy BW, Feeney PJ (1997) Experimental and computational approaches to estimate solubility and permeability in drug discovery and development settings. Adv Drug Deliv Rev 23:3-25. https://doi.org/10.1016/S0169409X(96)00423-1

27. Lipinski CA (2005) Capter 11 Filtering in Drug Discovery. Annu Rep Comput Chem 1:155-168. https://doi.org/10.1016/S15741400(05)01011-X

28. Buntrock RE (2002) ChemOffice Ultra 7.0. J Chem Inf Comput Sci 42:1505-1506. https://doi.org/10.1021/ci025575p

29. Zielesny A (2005) Chemistry Software Package ChemOffice Ultra 2005. Doi: https://doi.org/10.1021/ci050273j

30. Jin Z, Du X, Xu Y et al (2020) Structure of M pro from SARSCoV-2 and discovery of its inhibitors. Nature 582:289-293. https://doi.org/10.1038/s41586-020-2223-y

31. Nasution MAF, Toepak EP, Alkaff AH, Tambunan USF (2018) Flexible docking-based molecular dynamics simulation of natural product compounds and Ebola virus Nucleocapsid (EBOV NP): a computational approach to discover new drug for combating Ebola. BMC Bioinformatics 19:419. https://doi.org/10.1186/ s12859-018-2387-8

32. Berendsen HJC (1995) vd S., D.; van Drunen, R. Comput Phys Commun 91:43. https://doi.org/10.1016/0010-4655(95)00042-E

33. Lindahl E, Hess B, Van Der Spoel D (2001) GROMACS 3.0: a package for molecular simulation and trajectory analysis. Mol Model Annu 7:306-317. https://doi.org/10.1007/s008940100045

34. Berendsen HJC, Hess B, Lindahl E et al (2005) GROMACS: fast, flexible, and free. J Comput Chem 26:1701-1718. https://doi.org/ $10.1002 /$ jec. 20291

35. Hess B, Kutzner C, Van Der Spoel D, Lindahl E (2008) GROMACS 4: algorithms for highly efficient, load-balanced, and scalable molecular simulation. J Chem Theory Comput 4:435447. https://doi.org/10.1021/ct700301q

36. Zhang L, Zhang J, Yang J et al (2013) PriVar: A toolkit for prioritizing SNVs and indels from next-generation sequencing data. Bioinformatics 29:124-125. https://doi.org/10.1093/bioinforma tics/bts627

37. Páll S, Abraham MJ, Kutzner C et al (2014) Tackling exascale software challenges in molecular dynamics simulations with GROMACS. In: international conference on exascale applications and software. pp 3-27. Springer, Berlin. Doi: https://doi.org/10. 1007/978-3-319-15976-8_1

38. Khan RJ, Jha RK, Amera GM et al (2020) Targeting SARSCoV-2: a systematic drug repurposing approach to identify promising inhibitors against $3 \mathrm{C}$-like proteinase and 2 '-O-ribose methyltransferase. J Biomol Struct Dyn. https://doi.org/10.1080/ 07391102.2020.1753577

39. Van Aalten DMF, Bywater R, Findlay JBC et al (1996) PRODRG, a program for generating molecular topologies and unique molecular descriptors from coordinates of small molecules. J Comput Aided Mol Des 10:255-262. https://doi.org/10.1007/BF00355047

40. de Medeiros DJ, Cortopassi WA, Costa França TC, Pimentel AS (2012) ITP adjuster 1.0: A new utility program to adjust charges in the topology files generated by the PRODRG server. J Chem. https://doi.org/10.1155/2013/803151 
41. Wallace AC, Laskowski RA, Thornton JM (1995) LIGPLOT: a program to generate schematic diagrams of protein-ligand interactions. Protein Eng Des Sel 8:127-134. https://doi.org/10.1093/ protein/8.2.127

42. DE Pires V, Blundell TL, Ascher DB (2015) pkCSM: predicting small-molecule pharmacokinetic and toxicity properties using graph-based signatures. J Med Chem 58:4066-4072. https://doi. org/10.1021/acs.jmedchem.5b00104

43. Adeoye AO, Oso BJ, Olaoye IF et al (2020) Repurposing of chloroquine and some clinically approved antiviral drugs as effective therapeutics to prevent cellular entry and replication of coronavirus. J Biomol Struct Dyn. https://doi.org/10.1080/07391102.2020. 1765876

44. Kumari R, Kumar R, Lynn A (2014) G-mmpbsa -A GROMACS tool for high-throughput MM-PBSA calculations. J Chem Inf Model 54:1951-1962. https://doi.org/10.1021/ci500020m

45. Baker NA, Sept D, Joseph S et al (2001) Electrostatics of nanosystems: Application to microtubules and the ribosome. Proc Natl Acad Sci U S A 98:10037-10041. https://doi.org/10.1073/pnas. 181342398

46. Gogoi D, Chaliha AK, Sarma D et al (2017) Identification of potential type 4 cAMP phosphodiesterase inhibitors via 3D pharmacophore modeling, virtual screening, DFT and structural bioisostere design. Med Chem Res 26:3000-3014. https://doi.org/10. 1007/s00044-017-1998-3

47. Gaulton A, Bellis LJ, Bento AP et al (2012) ChEMBL: a largescale bioactivity database for drug discovery. Nucleic Acids Res 40:D1100-D1107. https://doi.org/10.1093/nar/gkr777
48. Bento AP, Gaulton A, Hersey A et al (2014) The ChEMBL bioactivity database: an update. Nucleic Acids Res 42:D1083-D1090. https://doi.org/10.1093/nar/gkt1031

49. Studio D (2008) Discovery Studio. Accelrys [21]. http://media. accelrys.com/webinars/DS-21-Series/6-19-FHG-pk.pdf

50. Sarma P, Shekhar N, Prajapat M et al (2020) In-silico homology assisted identification of inhibitor of RNA binding against 2019-nCoV N-protein (N terminal domain). J Biomol Struct Dyn. https://doi.org/10.1080/07391102.2020.1753580

51. Pant S, Singh M, Ravichandiran V et al (2020) Peptide-like and small-molecule inhibitors against Covid-19. J Biomol Struct Dyn. https://doi.org/10.1080/07391102.2020.1757510

52. Kuzuhara T, Iwai Y, Takahashi H et al (2009) Green tea catechins inhibit the endonuclease activity of influenza A virus RNA polymerase. PLoS Curr. https://doi.org/10.1371/currents.rrn1052

53. Gopalakrishnan SB, Kalaiarasi T, Subramanian R (2014) Comparative DFT study of phytochemical constituents of the fruits of cucumis trigonus Roxb. and cucumis sativus Linn. J Comput Methods Phys 2014:1-6. https://doi.org/10.1155/2014/623235

Publisher's Note Springer Nature remains neutral with regard to jurisdictional claims in published maps and institutional affiliations. 